\title{
ISOLATION AND CHARACTERIZATION OF ENDOPHYTIC FUNGI FROM CALOTROPIS PROCERA FOR THEIR ANTIOXIDANT ACTIVITY
}

\author{
VIPIN NAGDA ${ }^{1 *}$, ARCHANA GAJBHIYE ${ }^{1}$, DINESH KUMAR ${ }^{1,2}$ \\ ${ }^{1}$ Department of Biotechnology, Sir Padampat Singhania University, Udaipur - 313 601, Rajasthan, India. ${ }^{2}$ Department of Biotechnology, \\ B.N.P.G. College, Udaipur-313001, Rajasthan, India. Email: vipin.nagda@spsu.ac.in
}

Received: 11 November 2016, Revised and Accepted: 16 December 2016

\section{ABSTRACT}

Objective: To investigate the antioxidant activity of methanolic extract of endophytic fungi isolated from Calotropis procera plant.

Methods: The endophytic fungi were isolated from explants of leaf, stem, and flower of $C$. procera on potato dextrose broth (PDB) medium. The fungal isolates were mass cultured in PDB. The methanolic extracts of these fungi were prepared and evaluated for the antioxidant activity by 1,1 -diphenyl2-picryl-hydrazyl (DPPH) free radical scavenging assay and reducing power assay. The extracts were characterized for the presence of phenolics and flavonoids.

Results: A total of 8 endophytic fungi were isolated from C. procera explants. Out of these 8 fungal isolates, the crude extracts of two fungi, i.e. CPIMR-2 and CPIL-1 showed positive antioxidant activity. From the morphological characteristics, the isolates CPIMR-2 and CPIL-1 were identified as Penicillium spp. and Aspergillus spp., respectively. Both the isolates were found to possess antioxidant potential with \% inhibition value of $81.16 \%$ and $80.97 \%$ in the DPPH radical scavenging assay. The phytochemical screening of the methanolic extracts showed the presence of phenolics and flavonoids. The total flavonoids content in Penicillium species and Aspergillus species were found to be $130.50 \mu \mathrm{g} / \mathrm{mg}$ and $94.91 \mu \mathrm{g} / \mathrm{mg}$ of extracts, respectively. The total phenolic content was found to be $9.16 \mu \mathrm{g} / \mathrm{mg}$ and $12.13 \mu \mathrm{g} / \mathrm{mg}$ of extracts in Penicillium species and Aspergillus species, respectively.

Conclusions: Endophtyic fungi were found to be present in medicinal value plant $C$. procera. The probable bioactive component for antioxidant activity possessed by the fungi would be the flavonoids and phenolics. These metabolite produced by endophytic fungi from $C$. procera need to be explored further as potential source of novel natural antioxidant compound.

Keywords: Endophytes, Calotropis procera, Antioxidant, Radical scavenging, Reducing power, Flavonoids.

(C) 2017 The Authors. Published by Innovare Academic Sciences Pvt Ltd. This is an open access article under the CC BY license (http://creativecommons. org/licenses/by/4. 0/) DOI: http://dx.doi.org/10.22159/ajpcr.2017.v10i3.16125

\section{INTRODUCTION}

Antioxidants play a very important role in preventing cell damage. The diets containing antioxidants are recommended for health improvement as naturally derived antioxidant could delay or provide protection to living organisms from damage. Reactive oxygen species (ROS), e.g., $\mathrm{O}_{2}$ and $\mathrm{OH}^{-}$, are byproducts of normal metabolism and are found in all types of organisms from microbes to higher plants and animals. It has been established that ROS and free radical mediated reactions can cause oxidative damage to biomolecules (e.g., lipids, proteins, and DNA), eventually contributing to aging, cancer, atherosclerosis, coronary heart ailment, diabetes, Alzheimer's disease, and other neurodegenerative disorders, etc. $[1,2]$. Antioxidants are thought to be highly effective in the management of ROS-mediated tissue impairments.

Medicinal plants contain a wide variety of radical scavenging molecules such as phenolic compounds (e.g., phenolic acids, flavonoids, quinones, coumarins, lignans, lignin, stilbenes, and tannins), nitrogen compounds (e.g., alkaloids and amines), vitamins, terpenoids, and other endogenous metabolites [3-5]. In addition to plants, microorganisms have been regarded as an important source of novel metabolite with promising antibacterial, antimycotic, and antiviral activity. Fungi are one of the major sources of natural bioactive compounds [6]. Endophytes are recognized as rich sources of bioactive metabolites of multifold importance in medicine, agriculture, and industries [7]. Many endophytic fungi have been reported to produce novel antibacterial, antifungal, antiviral, antiinflammatory, antitumor, and other compounds belonging to the alkaloids, steroid, flavonoid, and terpenoids derivatives and other structure types [8].
Discovery of pestacin and isopestacin as antioxidant compounds from Pestalotiopsis microspora residing in Terminalia morobensis led to the exploration of antioxidant potential [9]. A new isobenzofuranone derivative 4,6-dihydroxy-5-methoxy-7-methylphthalide with antioxidant activity was obtained in Cephalosporium sp. from Sinarundinaria nitida [10]. Graphislactone A was isolated from Cephalosporium sp. an endophyte of Trachelospermum jasminoides [11]. The natural antioxidant cajaninstilbene acid, 3-hydroxy-4-prenyl-5methoxystibliline-2-carboxylic acid has been reported from Fusarium as endophyte of pigeon pea, Cajanus cajan [12], Xylaria species isolated from Ginkgo biloba and Chaetomium species isolated from Nerium oleander are some of the potential endophytes reported with a strong antioxidant activity due to their ability to produce phenolic and flavonoid $[13,14]$.

There is great need to isolate, characterize, and develop new natural compounds present in medicinal plant which are used as a traditional (Ayurvedic) medicine to treat diseases. Endophytes are reported to produce natural products similar as to that of the host plant. Calotropis procera is one such medicinally important plant which is not much explored for the endophytes and its bioactivities. The present investigation was performed to identify the endophytic fungi of $C$. procera for their antioxidant potential and characterization of the active biomolecules.

\section{MATERIALS AND METHODS}

Plant material

C. procera plant samples, viz., leaf, stem, and flower parts were collected for isolation of fungi from Udaipur Rajasthan, India. Most samples 
were collected during summer (temperature $35^{\circ} \mathrm{C} \pm 2^{\circ} \mathrm{C}$ ), the plant was authenticated by the Department of Biotechnology B.N.P.G. College, Udaipur, Rajasthan. Plant material was collected in a sterile container and carried to the laboratory. The material was used within few hours of collection. Fresh plant parts were used for isolation of plant associated fungi.

\section{Isolation of plant associated fungi}

Isolation of fungi was carried out using a modified method described by Schulz et al. [15]. The collected cut section of leaf, flower, and stem of $C$. procera was washed under running tap water for 15 minutes to remove the entire soil particle, and the plant samples were treated with detergent and then washed with sterile distilled water. Further surface sterilization of plant material was performed. The samples were transferred to a sterile conical flask and treated with $70 \%$ alcohol for 1 minute followed by $5 \%$ sodium hypochlorite treatment for 15 minute. The samples were finally rinsed with distilled water to eliminate the traces of any chemical left on the samples. After sterilization each plant sample was cut into small segments of $5 \times 5 \mathrm{~mm}$ size and placed on freshly prepared potato dextrose agar (PDA) plates supplemented with streptomycin $(500 \mathrm{mg} / \mathrm{L})$. The plates were incubated at $27^{\circ} \mathrm{C}$ until fungal growth appeared. The fungal colonies appeared on the plates were transferred to fresh PDA plates, further purified and maintained on the PDA by regular sub culturing.

\section{Morphological characterization}

The fungal isolates were characterized based on colonial characterization and microscopic investigation, for colonial characterization, parameters like color of the colony, filamentous, and mat type growth was considered. The slides of both old and fresh fungal cultures were prepared using lactophenol cotton blue stain [16] and observed under microscope (Olympus CH20i) at $\times 40$ and $\times 100$ magnification. In a microscopic investigation of the slides the structure, shape and patterns of mycelia, reproductive and nonreproductive structures, fruiting bodies, conidia, conidiophores were observed.

\section{Preparation of fungal crude extract}

Extraction of fungal secondary metabolite was performed according to the method described by Lin et al. [17] and Choudhary et al. [18]. Mycelia from 5 days old actively growing fungal culture were inoculated in $100 \mathrm{ml}$ potato dextrose broth in $250 \mathrm{ml}$ Erlenmeyer flasks. After 15 days of incubation at $28^{\circ} \mathrm{C} \pm 2^{\circ} \mathrm{C}$ in a rotary shaker $(100 \mathrm{RPM})$ culture broths were filtered with cheese cloth. The separated mycelia were soaked in methanol for 30 minutes and then crushed in homogenizer. The suspension was filtered with Whatman filter paper no.1. Filtrates were evaporated at $60^{\circ} \mathrm{C}$ till the residue was obtained. The residue was used as crude extract.

\section{Radical scavenging activity by 1,1-diphenyl-2-picryl-hydrazyl (DPPH) radical scavenging assay}

Various concentrations of fungal extracts $(20-100 \mu \mathrm{g} / \mathrm{ml}, 2.5 \mathrm{ml})$ were mixed with a methanolic solution of DPPH radicals $(0.1 \mathrm{~mm}, 0.5 \mathrm{ml})$. The mixture was shaken vigorously and left to stand in the dark for 30 minutes. The reduction in the DPPH radical concentration was determined by measuring the absorbance at $517 \mathrm{~nm}$. Methanol was taken as blank and DPPH solution without the extracts was taken as a control [19]. The percentage of inhibition of DPPH free radical activity was calculated using the equation:

Percent Inhibition $=\frac{\mathrm{Ac}-\mathrm{As}}{\mathrm{Ac}} \times 100$

Where "Ac" is the absorbance of control, and "As" is the absorbance of solution containing sample extracts. All assays were carried out in triplicate and the results were expressed as a mean \% value \pm standard deviation (SD).

\section{Reducing power assay}

The reducing potential of the extract was determined according to the method described by Oyaizu [20]. Different concentrations of methanolic extracts $(0.2,0.4,0.6,0.8,1.0 \mathrm{mg} / \mathrm{ml})$ were mixed with phosphate buffer ( $2.5 \mathrm{ml}, 0.2 \mathrm{M}, \mathrm{pH} 6.6)$ and potassium ferricyanide solution $(2.5 \mathrm{ml}, 1 \% \mathrm{w} / \mathrm{v})$. A layer of solution $(2.5 \mathrm{ml})$ was mixed with distilled water $(2.5 \mathrm{ml})$ and $\mathrm{FeCl}_{3}$ solution $(0.5 \mathrm{ml}, 0.1 \% \mathrm{w} / \mathrm{v})$ and the absorbance was measured at $700 \mathrm{~nm}$ in a spectrophotometer. Ascorbic acid (AA) was used as standard (positive control) for comparison of results. The high absorbance value of the reaction mixture indicates greater reductive potential. The assay was carried out in triplicate and the results were expressed as mean $\mathrm{OD} \pm \mathrm{SD}$.

\section{Screening of flavonoids}

The presence of flavonoids in methanolic extracts of endophytic fungi was carried out using the method described by Trease and Evans [21]. The fungal extract was warmed and filtered, and $200 \mu \mathrm{l}$ of $10 \%$ aqueous $\mathrm{NaOH}$ was added to the filtrate. The change in color was observed after addition of $\mathrm{NaOH}$. $\mathrm{HCl}$ was again added to this reaction mixture and further observed for disappearance of color.

Thin layer chromatography of the extract was carried out according to the method described by Wagner and Bladt [22] with some modifications. A thin strip of thin-layer chromatography (TLC) silica plate (TLC Silica gel 60 F254, Merck) was impregnated with the fine drop of extract at marked places and allowed to air dry. The plate was developed in a chromatography chamber using a solvent system consisting of ethyl acetate:glacial acetic acid:formic acid:distilled water in a ratio 12.1:1.3:1.1:2.8. After the successful development, the plate was examined under the ultraviolet chamber at $366 \mathrm{~nm}$ for the presence of any spots.

\section{Determination of total flavonoid content}

Total flavonoid content was measured with the aluminum chloride assay. $1 \mathrm{ml}$ of sample was mixed with $4 \mathrm{ml}$ of distilled water and $0.3 \mathrm{ml}$ of sodium nitrite solution $(5 \% \mathrm{w} / \mathrm{v})$ and was allowed to stand for 5 minutes. $0.3 \mathrm{ml}$ of aluminum chloride solution $(10 \%)$ was added to the sample mix and after 1 minute, $0.2 \mathrm{ml}$ of $1 \mathrm{M} \mathrm{NAOH}$ was added. The volume was made up to $10 \mathrm{ml}$ with distilled water and mixed well. Tubes were observed for development of yellow color. The absorbance was measured at $510 \mathrm{~nm}$ in spectrophotometer [23,24]. Varying the concentration of quercetin $(100-1000 \mu \mathrm{g} / \mathrm{ml})$ was used for preparing the standard curve. The experiment was performed in triplicates and the standard curve was plotted using the OD values obtained for quercetin. The total flavonoid content was calculated from standard curve and the result was expressed as mg quercetin equivalent per gram dry weight of fungal extract, the values were expressed as mean \pm SD.

\section{Determination of total phenolic contents}

The concentrations of phenolics in fungal extracts were determined using spectrophotometric methods described by Singleton et al. [25]. Methanolic solution of the extract $(1 \mathrm{mg} / \mathrm{ml})$ was used for the analysis. The reaction mixture was prepared by mixing $0.5 \mathrm{ml}$ of methanolic extract with $2.5 \mathrm{ml}$ of $10 \%$ Folin-Ciocalteu's reagent dissolved in water and $2.5 \mathrm{ml} 7.5 \% \mathrm{NaHCO}_{3}$. Blank was concomitantly prepared, containing $0.5 \mathrm{ml}$ methanol, $2.5 \mathrm{ml} 10 \%$ Folin-Ciocalteu's reagent (prepared with water), and $2.5 \mathrm{ml}$ of $7.5 \%$ of $\mathrm{NaHCO}_{3}$. The samples were thereafter incubated in a thermostat at $45^{\circ} \mathrm{C}$ for 45 minutes. The absorbance was checked using spectrophotometer at $765 \mathrm{~nm}$. The samples were prepared in triplicate for each analysis and the mean value of absorbance was obtained. The same procedure was followed for the standard curve of gallic acid. The phenolic content in the fungal extracts was derived from the standard curve and the results were expressed as mg of gallic acid eq. per gram dry weight of extract.

\section{RESULTS AND DISCUSSION}

Isolation and morphological characterization of endophytic fungi From stem, flower, and leaf explants of C. procera total 8 fungal isolates were obtained. The isolates were found to be slow growers with a minimum time for the appearance of the mycelia ranging from 48 to $96 \mathrm{hrs}$. The fungal isolates were nomenclatures based on the name of the plant and the plant part from which it was obtained (Table 1). 
Table 1: Fungal endophytes obtained from different plant parts and their characteristics

\begin{tabular}{lllll}
\hline S. No. & Explant & No. of fungal isolates & Isolates & Colonical characteristics \\
\hline 1 & Leaf Midrib & 3 & CPIMR-1 & White filamentous, filiform \\
& & & CPIMR-2 & Fast growing colonies, phialide, metulae, gray color \\
& & 2 & CPIMR-3 & White filamentous, filiform \\
2 & Leaf & 1 & CPIL-1 & Fast growing colonies, yellow-brown, phialides, metulae \\
& & 2 & CPIL-2 & Dark brown, irregular, undulate \\
3 & Stem & CPIS-1 & White color, irregular and undulate \\
4 & Flower & CPIF-2 & White, circular, entire \\
& & & White color, filamentous and filiform \\
\hline
\end{tabular}

The colonical characteristics of the isolates showed velvety, furrowed, and mottled type of growth with gray and yellow-brown colored colony on PDA medium. The microscopic observation of 7 days old mycelium stained with lactophenol cotton blue showed the presence of conidiophore, spores, metulae, and phialides structures in isolates. CPIMR-2 and CPIL-1 were observed with spore forming mycelium (Fig. 1). From this pattern, the fungal isolates CPIMR-2 and CPIL-1 were identified as Penicillium species and Aspergillus species, respectively.

Various medicinal plants were reported in the presence of endophytes in different plant parts where Calotropis is one of the less explored plants for their fungal endophytes. So far two species of Calotropis, $C$. procera, and Calotropis gigantea were studied for the endophytic fungal biodiversity and were reported with endophytes in leaf midrib, leaf lateral, stem, and flower parts [26,27]. In this study, fungal isolates were obtained from flower and leaf explants. Two of the fungal isolates that we obtained from the leaf were identified to be Penicillium species and Aspergillus species. Similar endophytes were reported by Khan et al. (2007) in C. procera that include Aspergillus and Penicillium species along with Candida and Phoma species from stem part [26]. Asperg illus and Penicillium species were also reported in other medicinal plants, viz., Hibiscus tiliaceus, Catharanthus roseus, Salvadora oleoides, and Biophytum sensitivum [28-30].

\section{Radical scavenging activity by DPPH assay}

Out of total 8 fungi, the extracts of Penicillium species (CPIMR-2) and Aspergillus species (CPIL-1) showed positive results for antioxidant activity by DPPH radical scavenging assay. A decrease in the oxidation activity of DPPH radical was observed in both the fungal extracts due to their radical scavenging ability. A maximum inhibition of DPPH oxidation was found to be $81.00 \pm 0.71 \%$ in the methanolic extract of CPIMR-2 at a concentration of $60 \mu \mathrm{g} / \mathrm{ml}$ and $80.97 \pm 0.78 \%$ in CPIL-1 at a concentration of $80 \mu \mathrm{g} / \mathrm{ml}$ which was considered to be significant as compared to the percent inhibition values obtained with AA as a standard antioxidant (Fig. 2).

In our study, the methanolic extract of two endophytic isolates CPIMR-2, i.e., Penicillium species and CPIL-1, i.e., Aspergillus species has showed an increasing radical scavenging effect with increased concentration of crude extract. The antioxidant activity was encouraging $(80.27 \%$ and $79.62 \%$ ) even at $60-80 \mu \mathrm{g} / \mathrm{ml}$ in comparison to the activity reported in the extract of endophytic fungi Aspergillus species and Penicillium species isolated from Hugonia mystax which showed $88.1 \%$ and $36.5 \%$ at $100 \mu \mathrm{g} / \mathrm{ml}$ concentration [31]. A 72\% inhibition of oxidation was reported in Aspergillus fumigatus isolated from Gracinia species [32]. Similarly, $70 \%$ inhibition at $200 \mu \mathrm{g} / \mathrm{ml}$ concentration was found to be reported in crude extracts of Penicillum species from Centella asiatica, whereas, $53.12 \%$ inhibition was reported in extract of fungi isolated from Ocimum sanctum at $100 \mu \mathrm{g} / \mathrm{ml}$ [33-34]. In comparison to these values the potential of crude extracts of CPIMR-2 and CPIL- 1 for quenching the free radical (DPPH) can be considered to be potential resources for antioxidant actives.

\section{Reducing power}

The reductive ability of sample extracts was determined by measuring its ability to transform $\mathrm{Fe}^{3+}$ to $\mathrm{Fe}^{2+}$. The color change of the test solution from yellow to various shades of green and blue were observed

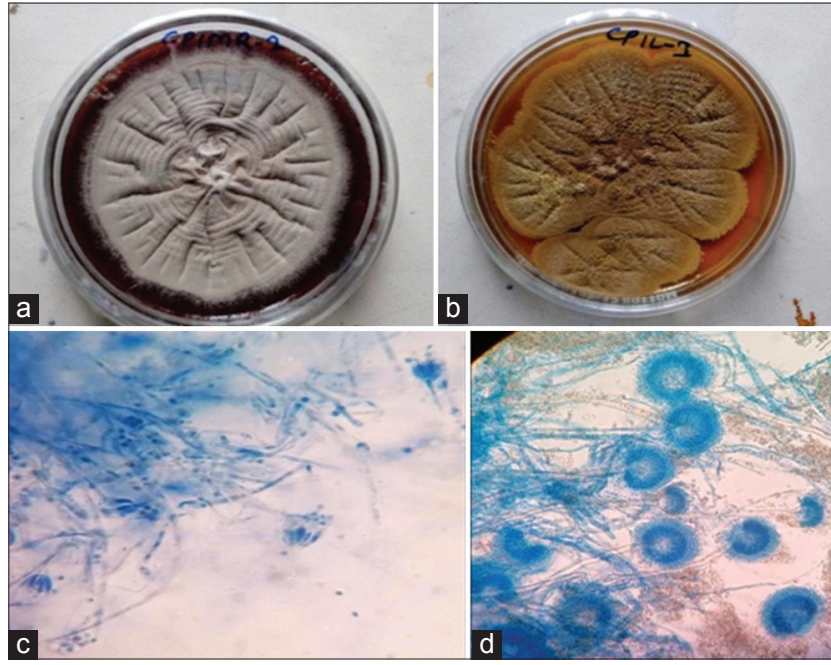

Fig. 1: Fungal endophytes obtained from leaf and leaf midrib of Calotropis procera. ( $a$ and b) Fungal growth of CPIMR-2 and CPIL-1, respectively, on potato dextrose agar after incubation of $96 \mathrm{hrs}$ at $27^{\circ}$ C. (c and d) Microscopic view of CPIMR-2 and CPIL-1, respectively, stained with lactophenol cotton blue observed under $\times 100$



Fig. 2: Percent inhibition of 1,1-diphenyl-2-picryl-hydrazyl free radical activity by the fungal extracts and ascorbic acid standard at various concentrations. Values are mean \pm standard deviation of three replication $(n=3)$

depending on concentration and the reducing power of the compounds present in fungal extracts. Fungal extracts of CPIMR-2 (Penicillium sp.) and CPIL-1 (Aspergillus sp.) were observed positive for reducing power, similar to that of DPPH assay. The reducing power of the extracts and standard AA increased with an increase in the concentration as appeared form the absorbance (OD) values. The fungal extracts showed less reducing power as compared to that of $\mathrm{AA}$, which was analyzed as a positive control (Fig. 3).

The methanolic extracts of both the fungi, i.e., Aspergillus species (CPIL-1) and Penicillium species (CPIMR-2) showed a potent reducing 
power. Maximum reducing power was observed at a concentration of $0.1 \mathrm{mg} / \mathrm{ml}$ in both the extracts. Among the two endophytes, CPIL-1 exhibited high reducing power. Similar results for reducing power in the crude extracts of endophytes have been reported in studies by Kekuda et al. [35]. In the studies reported by Zheng et al., the aqueous extract of Tolypocladium species isolated from wild Cordyceps sinensis has shown a moderate reducing power activity [36].

\section{Qualitative analysis of flavonoids}

The results of the qualitative phytochemical analysis inferred that the methanolic extract of fungi contains flavonoids. A yellow was developed after addition of $\mathrm{NaOH}$ which disappeared on neutralization with dil. $\mathrm{HCl}$. A change in color from yellow to colorless on addition of dil. $\mathrm{HCl}$ was an indication of the presence of flavonoids. In TLC analysis of the extracts, the chromatogram developed showed a single dark spot in the extract of CPIMR-2 and a fluorescent blue spot in the extract of CPIL-1 against a fluorescent green background (Fig. 4). The color of flavonoids

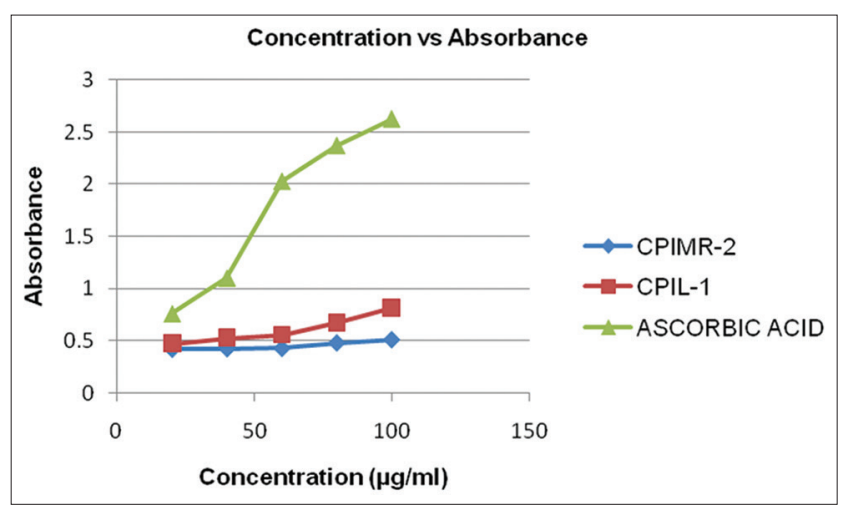

Fig. 3: Reducing ability of methanolic extracts of fungal isolates compared with ascorbic acid as standard at increasing concentrations. Values are mean \pm standard deviation of three replication $(n=3)$

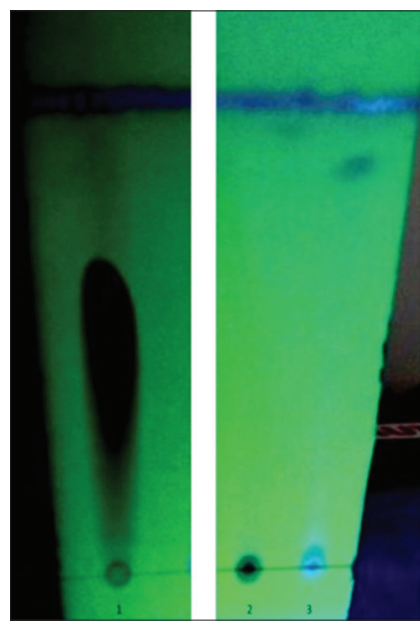

Fig. 4: Chromatogram of (1) quercetin and methanolic extracts of fungi (2) CPIMR-2 and (3) CPIL-1 developed by thin-layer chromatography using solvent system ethyl acetate:formic acid:glacial acetic acid:water. Dark spots were observed in ultraviolet light against green background confirming the presence of flavonoids may vary from dark to yellow, green, or blue fluorescent in U.V light based on the chemical structure of flavonoid.

\section{Total flavonoids and phenolics}

The concentration of flavonoids and phenolics in the two fungal extracts of the C. procera that showed a positive test for RSA and reducing power (i.e., CPIMR-2 and CPIL-1) was determined using a spectrophotometric method. The total flavonoid content in the extracts was expressed in terms of quercetin equivalent using standard curve equation $\mathrm{Y}=0.0007 \mathrm{X}, \mathrm{R}^{2}=0.9586$. In CPIMR-2 and CPIL-1, the flavonoid content was found to be $130.50 \pm 6.111 \mathrm{mg} / \mathrm{g}$ and $94.91 \pm 4.483 \mathrm{mg} / \mathrm{g}$ dry weight of fungal extract, respectively (Table 2).

The total phenolic content was expressed in terms of gallic acid equivalent using standard calibration curve equation $\mathrm{Y}=0.0177 \mathrm{X}$, $\mathrm{R}^{2}=0.8987$. The phenolic content was found to be $9.16 \pm 0.71 \mathrm{mg} / \mathrm{g}$ and $12.13 \pm 3.96 \mathrm{mg} / \mathrm{g}$ of dry weight of extract in CPIMR-2 and CPIL-1, respectively (Table 2). The presence of similar quantities of phenolic content was also reported in methanolic extract of Aspergillus species and Penicillium species isolated from Tabebuia argentea (19.20 and $16.23 \mathrm{mg} / \mathrm{GAE} / \mathrm{g}$ ) [37]

Antioxidant property of natural products is attributed to the secondary metabolites of the plant kingdom, particularly phenolics and flavonoids, many polyphenols, tannic acid has been shown to possess antioxidant activity [38]. Various fungal species have been also reported to produce these compounds and found to possess the antioxidant potential as well [39]. The production of these secondary metabolites (i.e., phenolics and flavonoids) has been reported in different endophytic fungi, including Aspergillus nidulans and Aspergillus oryzae isolated from G. biloba [40] and Aspergillus niger and Fusarium oxysporum isolated from Crotalaria pallida [37].

In various studies, the population and biodiversity of the fungal endophytes have been found to be varying as the environmental conditions under which the host is growing, the host plant composition, as well as seasonal variation, affects the endophytes population [41]. Some of the medicinal characteristics of the host plant may also be found to be similar to that of the endophytes. C. procera is one of such medicinal plant which has been studied and reported with various medicinal potential such as anthelmintic properties that relieves strangury, cure ulcers, cure piles, asthma, and wounds [42]. The compounds phenolic acids, flavonoids, and tannins are the most commonly found polyphenolic compounds in plant extracts [43]. The phenolics of $C$. procera were reported to possess the antioxidant property [44]. The isolates of $C$. procera CPIMR-2 and CPIL-1 were also found to possess the similar properties. This can be correlated as one of the plant microbe interaction mechanism where the host and the endophyte produce and possess similar characteristics. From the findings of our studies, the compounds flavonoids and phenolics are the key bioactives responsible for the antioxidant and reducing power. These fungal isolates should be considered as the resource for production of antioxidants and its medicinal importance.

\section{ACKNOWLEDGMENT}

The authors are grateful to Prof. P C Deka, Vice Chancellor, Sir Padampat Singhania University, Udaipur, Rajasthan, India, for his valuable guidance and support during the research work. We also acknowledge the technical help and suggestions given by Mr. Dinesh Kumar Chhatwani, Research Scholar, Department of Biotechnology, Sir Padampat Singhania University, Udaipur Rajasthan, India.

Table 2: Total flavonoid and phenolic content present in the extracts of the endophytic fungal isolates

\begin{tabular}{lll}
\hline Sample & Total flavonoid content in $\mathbf{~ m g} / \mathbf{g}$ of extracts (mean \pm SD) & Total phenol content in mg/g of extracts (mean \pm SD) \\
\hline CPIMR-2 (Penicillium sp.) & $130.50 \pm 6.111$ & $9.16 \pm 0.71$ \\
CPIL-1 (Aspergillus sp.) & $94.91 \pm 4.483$ & $12.13 \pm 3.96$ \\
\hline
\end{tabular}

*Values are mean \pm SD of three triplicates $(n=3)$, SD: Standard deviation 


\section{REFERENCES}

1. Halliwell B. Free radicals and antioxidants: A personal view. Nutr Rev 1994;52:253-65.

2. Finkel T, Holbrook NJ. Oxidants, oxidative stress and the biology of ageing. Nature 2000;408(6809):239-47.

3. Kähkönen MP, Hopia AI, Vuorela HJ, Rauha JP, Pihlaja K, Kujala TS, et al. Antioxidant activity of plant extracts containing phenolic compounds. J Agric Food Chem 1999;47(10):3954-62.

4. Zheng W, Wang SY. Antioxidant activity and phenolic compounds in selected herbs. J Agric Food Chem 2001;49(11):5165-70.

5. Cai Y, Luo Q, Sun M, Corke H. Antioxidant activity and phenolic compounds of 112 traditional Chinese medicinal plants associated with anticancer. Life Sci 2004;74(17):2157-84.

6. Bérdy J. Bioactive microbial metabolites. J Antibiot (Tokyo) 2005;58(1):1-26.

7. Tan RX, Zou WX. Endophytes: A rich source of functional metabolites. Nat Prod Rep 2001;18(4):448-59.

8. Yu H, Zhang L, Li L, Zheng C, Guo L, Li W, et al. Recent developments and future prospects of antimicrobial metabolites produced by endophytes. Microbiol Res 2010;165(6):437-49.

9. Harper JK, Arif AM, Ford EJ, Strobel GA, Porco JA, Tomer DP. Pestacin a 1, 3-dihydro isobenzofuran from Pestalotiopsis microspora possessing antioxidant and antimycotic activities. Tetrahedron 2003;59(14):2471-6.

10. Huang XZ, Zhu Y, Guan XL, Tian K, Guo JM, Wang HB, et al. A novel antioxidant isobenzofuranone derivative from fungus Cephalosporium sp.AL031. Molecules 2012;17(4):4219-24.

11. Song YC, Huang WY, Sun C, Wang FW, Tan RX. Characterization of graphislactone $\mathrm{A}$ as the antioxidant and free radical-scavenging substance from the culture of Cephalosporium sp. IFB-E001, an endophytic fungus in Trachelospermum jasminoides. Biol Pharm Bull 2005;28(3):506-9

12. Zhao J, Fu Y, Luo M, Zu Y, Wang W, Zhao C, et al. Endophytic fungi from pigeon pea [Cajanus cajan (L.) Millsp.] produce antioxidant Cajaninstilbene acid. J Agric Food Chem 2012;60(17):4314-9.

13. Huang WY, Cai YZ, Xing J, Corke H, Sun M. A potential antioxidant resource: Endophytic fungi from medicinal plants. Econ Bot 2007;61:14-30.

14. Liu X, Dong M, Chen X, Jiang M, Lv X, Yan G. Antioxidant activity and phenolics of an endophytic Xylaria sp. from Ginkgo biloba. Food Chem 2007;105(2):548-54.

15. Schulz B, Wanke U, Draeger S, Aust HJ. Endophytes from herbaceous plants and shrubs: Effectiveness of surface sterilization methods. Mycol Res 1993;97(12):1447-50

16. Goveas SW, Madtha R, Nivas SK, D'Souza L. Isolation of endophytic fungi from Coscinium fenestratum-a red listed endangered medicinal plant. Euras J Bio Sci 2011;5(4):48-53.

17. Lin Y, Wang J, Wu X, Zhou S, Vrijmoed LL, Jones EG. Anovel compound enniatin $\mathrm{G}$ from the mangrove fungus Halosarpheia sp.(strain\# 732) from the South China sea. Aust J Chem 2002;55(3):225-7.

18. Choudhary MI, Musharraf SG, Mukhmoor T, Shaheen F, Ali S, Rahman AU. Isolation of bioactive compounds from Aspergillus terreus. Z Naturforsch B 2004;59:324-8.

19. Babu DR, Rao GN. Antioxidant properties and electrochemical behavior of cultivated commercial Indian edible mushrooms. J Food Sci Technol 2013;50(2):301-8.

20. Oyaizu M. Studies on products of browning reaction--antioxidative activities of products of browning reaction prepared from glucosamine. Jpn J Nutr 1986;44(6):307-15.

21. Trease GE, Evans WC. Pharmacognosy. $13^{\text {th }}$ ed. London: ELBS, Bailliere Tindall; 1989. p. 345-6.

22. Wagner H, Bladt S. Plant Drug Analysis: A Thin Layer Chromatography atlas. Heidelberg: Springer Science \& Business Media; 1996.
23. Sathishkumar T, Baskar R, Shanmugam S, Rajasekaran P, Sadasivam S, Manikandan V. Optimization of flavonoids extraction from the leaves of Tabernaemontana heyneana Wall. using L16 Orthogonal design. Nat Sci 2008;6(3):10-21.

24. Patel VR, Patel PR, Kajal SS. Antioxidant activity of some selected medicinal plants in western region of India. Adv Biol Res 2010;4(1):23-6.

25. Singleton VL, Orthofer R, Lamuela-Raventos RM. Analysis of total phenols and other oxidation substrates and antioxidants by means of folin-ciocalteu reagent. Method Enzymol 1999;299:152-78.

26. Khan R, Shahzad S, Choudhary MI, Khan SA, Ahmad A. Biodiversity of the endophytic fungi isolated from Calotropis procera (Ait.) R. Br. Pak J Bot 2007;39(6):2233-9.

27. Selvanathan S, Indrakumar I, Johnpaul M. Biodiversity of the endophytic fungi isolated from Calotropis gigantea (L.) R. Br. Rec Res Sci Technol 2011;3(4):94-100

28. Kharwar RN, Verma VC, Strobel G, Ezra D. The endophytic fungal complex of Catharanthus roseus (L.) G. Don. Curr Sci 2008;95:228-33.

29. Dhankhar S, Kumar S, Dhankhar S, Yadav JP. Antioxidant activity of fungal endophytes isolated from Salvadora oleoides Decne. Int J Pharm Pharm Sci 2012;4(2):380-5.

30. Kalita P, Tapan BK, Pal TK, Kalita R. Estimation of total flavonoids content (TFC) and anti oxidant activities of methanolic whole plant extract of Biophytum sensitivum Linn. J Drug Deliv Ther 2013;3(4):33-7.

31. Abirami G, Boominathan M. Antimicrobial activity of endophytic fungi isolated from medicinal plant Hugonia mystax L. J Acad Ind Res 2016;4(12):257-62.

32. Ruma K, Kumar S, Prakash HS. Antioxidant, anti-inflammatory, antimicrobial and cytotoxic properties of fungal endophytes from Garcinia species. Int J Pharm Pharm Sci 2013;5(3):889-97.

33. Devi NN, Prabakaran JJ, Wahab F. Phytochemical analysis and enzyme analysis of endophytic fungi from Centella asiatica. Asian Pac J Trop Biomed 2012;2(3):1280-84.

34. Sharma R, Kumar BS. Isolation characterization and antioxidant potential of endophytic fungi of Ocimum sanctum Linn. Indian J Appl Res 2013;3(7):5-10.

35. Kekuda TP, Prashith TR, Shobha KS, Onkarappa R. Potent insecticidal activity of two Streptomyces species isolated from the soils of Western ghats of Agumbe, Karnataka. J Nat Pharm 2010;1(1):30-2.

36. Zheng LP, Gao LW, Zhou JQ, Sima YH, Wang JW. Antioxidant activity of aqueous extract of a Tolypocladium sp fungus isolated from wild Cordyceps sinensis. Afr J Biotechnol 2008;7(17):3004-10.

37. Govindappa M, Bharath N, Shruthi HB, Santoyo G. In vitro antioxidant activity and phytochemical screening of endophytic extracts of Crotalaria pallida. Free Radic Antioxid 2011;1(3):79-86.

38. Lopes GK, Schulman HM, Hermes-Lima M. Polyphenol tannic acid inhibits hydroxyl radical formation from Fenton reaction by complexing ferrous ions. BBA Gen Subj 1999;1472(1-2):142-52.

39. Song TY, Yen GC. Antioxidant properties of Antrodia camphorata in submerged culture. J Agric Food Chem 2002;50(11):3322-7.

40. Qiu M, Xie RS, Shi Y, Zhang H, Chen HM. Isolation and identification of two flavonoid-producing endophytic fungi from Ginkgo biloba L. Ann Microbiol 2010;60(1):143-50.

41. Hata K, Futai K, Tsuda M. Seasonal and needle age-dependent changes of the endophytic mycobiota in Pinus thunbergii and Pinus densiflora needles. Can J Bot 1998;76(2):245-50.

42. Bors W, Saran M, Elstner EF. Screening for plant antioxidants. In: Plant Toxin Analysis. Berlin, Heidelberg: Springer; 1992. p. 277-95.

43. Wolfe K, Wu X, Liu RH. Antioxidant activity of apple peels. J Agric Food Chem 2003;51(3):609-14.

44. Basile A, Giordano S, López-Sáez JA, Cobianchi RC. Antibacterial activity of pure flavonoids isolated from mosses. Phytochemistry 1999;52(8): 1479-82. 